\section{Low Temperature Water Gas Shift over Gold Catalysts}

\section{Donka Andreeva}

Institute of Catalysis, Bulgarian Academy of Sciences

'Acad G Bonchev' str, bl 11, 1113 Sofia, Bulgaria,

E-mail: andreev@ic.bas.bg

\section{Received: 11 February 2002}

This review summarizes the results reported in the literature on the water gas shift (WGS) over goldcontaining catalysts. Attention is focused on the influence of the preparation method and the nature of the support on the gold dispersion and WGS activity. Special emphasis is paid to the enhanced reducibility of the metal oxide support in the presence of gold. Some aspects of the reaction mechanism of the WGS are discussed.
The water gas shift (WGS) is one of the oldest catalytic processes employed in the chemical industry:

$$
\mathrm{CO}+\mathrm{H}_{2} \mathrm{O} \leftrightarrow \mathrm{CO}_{2}+\mathrm{H}_{2}(\Delta \mathrm{H}=-41.1 \mathrm{~kJ} / \mathrm{mol})
$$

This reaction provides an economic route to the production of hydrogen and it is a principal step in the production of ammonia and ammonia-based fertilizers. The WGS usually proceeds in two steps: high-temperature $(\mathrm{HT})$ - over iron-based catalysts and low-temperature (LT) - over copper-based catalysts. Owing to its industrial importance, the WGS and the catalysts used have been the subject of many studies (1 - 4).

Recently, there is renewed interest in this reaction because of its relevance as a means of producing pure hydrogen for use in the development of fuel-cell power systems. Another reason for the increased interest is the key role of the WGS in automobile exhaust processes, since the hydrogen produced is a very effective reductant for $\mathrm{NO}_{\mathrm{x}}$ removal.

Many authors have studied the catalytic activity of supported metals in the WGS (5 - 10). Grenoble et al studied this reaction in detail at atmospheric pressure and 270 $380^{\circ} \mathrm{C}$ over noble metals supported on alumina (5), and found the order of activity at $300^{\circ} \mathrm{C}$ to be: $\mathrm{Ru}>\mathrm{Pt}>\mathrm{Os}>\mathrm{Pd}$ $>\mathrm{Rh}>\mathrm{Ir}$. The support effect was found to decrease in the order: $\mathrm{Pt} / \mathrm{Al}_{2} \mathrm{O}_{3}>>\mathrm{Pt} / \mathrm{SiO}_{2}>\mathrm{Pt} / \mathrm{C}$. Recently, Yue Li et al (8) reported on the activity of $\mathrm{Cu}$ - and $\mathrm{Ni}$-supported cerium oxide catalysts for the LT WGS. A promoting effect of copper on the WGS activity of iron oxide in a medium temperature range has also been established (11).

A rapidly accelerating interest in catalytically active gold-based systems has occurred during the last decade. The research of $\mathrm{M}$. Haruta et al has dramatically changed the perception of gold nobility $(12,13)$. Using appropriate preparation methods and supports, these authors showed that catalysts based on highly dispersed gold particles are very active in a number of important reactions at low temperatures (12 - 15). The addition of gold to some oxide systems leads to an increase in the catalytic activity as a result of the interaction between the nanosized gold particles and the support. The structure and properties of the gold/metal oxide interface are the result of this specific interaction. One of the most critical points in tuning catalysis by gold is "to design the architecture of the perimeter interface between gold and support" (12). Burke has observed that extremely small gold clusters manifest unusual properties, eg, the ability to co-ordinate more oxygen and/or hydroxyl groups and therefore, to be very promising for oxidation reactions $(16,17)$. Recently, Bond and Thompson have critically reviewed the results on gold-containing catalysts reported in the literature $(18,19)$. The design of active gold catalysts has several crucial requirements, eg, choice of appropriate support and preparation method with a view to obtain well dispersed gold particles on the surface and a good interaction between gold and the support. 
The WGS over gold catalysts had not been studied before we started our investigations, except for some results on the hydrogenation of $\mathrm{CO}_{2}(20)$, and the objective of this review is to summarize our results to date.

\section{Measurements of Catalytic Activity}

The results are presented in chronological order. In 1995 high catalytic activity for the WGS was found for the first time using $\mathrm{Au} / \mathrm{Fe}_{2} \mathrm{O}_{3}$ at low temperatures $(21,22)$. Over this catalyst, $\mathrm{CO}$ conversion starts at $120^{\circ} \mathrm{C}$, its activity exceeding that of the most efficient LT WCS catalyst known previously, namely, the industrial $\mathrm{CuO} / \mathrm{ZnO} / \mathrm{Al}_{2} \mathrm{O}_{3}(23)$, under the same conditions. A strong dependence of the activity on the gold dispersion and the preparation method has been observed (22). IR and TPD data pointed to an increased concentration of hydroxyl groups on the $\mathrm{Au} / \mathrm{Fe}_{2} \mathrm{O}_{3}$ sample when compared with the pure iron oxide support. On the basis of these results it was suggested that the WGS proceeds via an associative mechanism. The essential aspects are the dissociative adsorption of water on ultrafine gold particles, followed by spillover of active hydroxyl groups onto adjacent sites of ferric oxide. The formation and decomposition of intermediate species is accompanied by the redox transfer $\mathrm{Fe}^{3+} \leftrightarrow \mathrm{Fe}^{2+}$ in $\mathrm{Fe}_{3} \mathrm{O}_{4}$ (22). Our conclusion was that the support plays an important role in the WGS activity. It could therefore be presumed that gold deposited on readily reducible metal oxides, eg $\mathrm{CO}_{3} \mathrm{O}_{4}$, would be active for WCS, while that

Table 1 WCS Activity of Catalysts Based on Supports of Different Crystalline State (based on References 26, 27)

\begin{tabular}{|c|c|c|c|}
\hline Catalysts & $\begin{array}{c}\text { Atomic } \\
\text { ratio, } \\
\text { Au:Me }\end{array}$ & $\begin{array}{c}\text { BET } \\
\text { surface } \\
\text { area, } \\
\mathrm{m}^{2} / \mathrm{g}\end{array}$ & ${ }^{\mathrm{T}_{1 / 2}{ }^{1},}$ \\
\hline $\mathrm{Au} / \mathrm{Fe}_{2} \mathrm{O}_{3}(\mathrm{Cr})^{2}$ & $1: 22.6$ & 59 & 160 \\
\hline $\mathrm{Au} / \mathrm{ZnO}(\mathrm{am}-\mathrm{ch})^{3}$ & $1: 26.0$ & 70 & 305 \\
\hline $\mathrm{Au} / \mathrm{ZrO}_{2}$ (cr) & $1: 24.0$ & 26 & 150 \\
\hline $\mathrm{Au} / \mathrm{ZrO}_{2}(\mathrm{am})^{4}$ & $1: 24.0$ & 85 & 305 \\
\hline $\mathrm{Au} / \mathrm{TiO}_{2}(\mathrm{Cr})$ & $1: 24.0$ & 71 & 130 \\
\hline $\mathrm{Au} / \mathrm{TiO}_{2}(\mathrm{am})$ & $1: 24.0$ & 95 & 300 \\
\hline $\mathrm{Au} / \mathrm{Fe}_{2} \mathrm{O}_{3}-\mathrm{ZnO}(\mathrm{am}-\mathrm{ch})$ & 1:21.4:1.3 & 69 & 230 \\
\hline $\mathrm{Au} / \mathrm{Fe}_{2} \mathrm{O}_{3}-\mathrm{ZrO}_{2}$ (am-ch) & $1: 21.4: 1.3$ & 74 & 260 \\
\hline
\end{tabular}

${ }^{1}$ temperature for $50 \%$ CO conversion

${ }^{2}$ well crystallized

${ }^{3}$ amorphous character

${ }^{4}$ amorphous

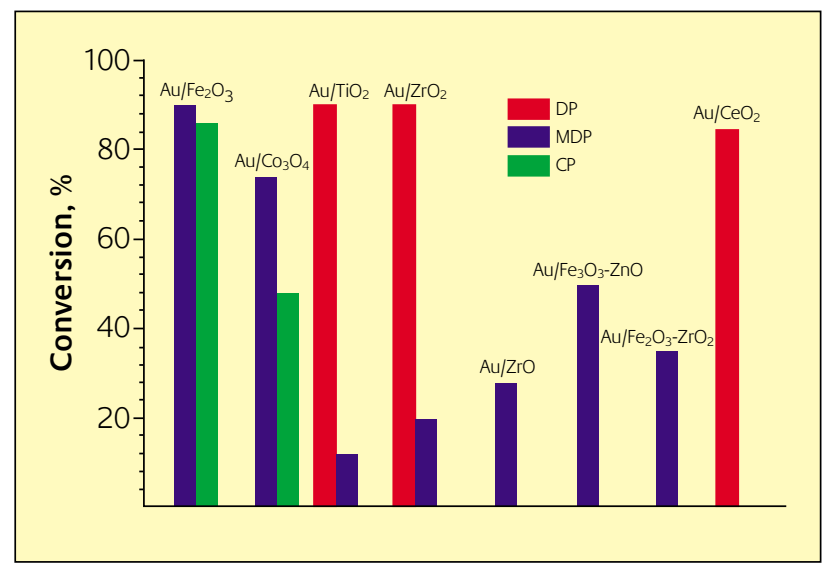

Figure 1

Catalytic activity in WCS (degree of CO conversion) at $200^{\circ} \mathrm{C}$ for goldbased samples, prepared by different techniques: DP - depositionprecipitation; MDP - modified version of deposition-precipitation; $C P$ coprecipitation. The data are based on results given in references 21 , 22, 24-27 and 29

deposited on hardly reducible oxides, such as $\mathrm{TiO}_{2}$ and $\mathrm{ZrO}_{2}$, would not be active in this reaction. The following order of the catalytic activity was established experimentally $(24-26)$ :

$$
\mathrm{Au} / \mathrm{Fe}_{2} \mathrm{O}_{3} \cong \mathrm{Au} / \mathrm{TiO}_{2} \cong \mathrm{Au} / \mathrm{ZrO}_{2}>\mathrm{Au} / \mathrm{CO}_{3} \mathrm{O}_{4}
$$

The activity found for the titania and zirconia supports was therefore surprisingly high.

The order found for the catalytic activity is discussed below in the reaction mechanism section. Here, it should be noted only that the $\mathrm{Au} / \mathrm{CO}_{3} \mathrm{O}_{4}$ catalyst was very rapidly deactivated. Haruta et al have reported a higher catalytic activity for $\mathrm{Au} / \mathrm{TiO}_{2}$ catalysts in the WGS in comparison with $\mathrm{Cu} / \mathrm{ZnO} / \mathrm{Al}_{2} \mathrm{O}_{3}, \mathrm{Au} / \mathrm{ZnO}, \mathrm{Au} / \mathrm{Fe}_{2} \mathrm{O}_{3}$ and $\mathrm{Au} / \mathrm{Al}_{2} \mathrm{O}_{3}$ (28).

In the search for novel, more stable and efficient supports for gold catalysts for the WCS, mixed oxide supports $\left(\mathrm{Fe}_{2} \mathrm{O}_{3}-\right.$ $\mathrm{ZnO}$ and $\mathrm{Fe}_{2} \mathrm{O}_{3}-\mathrm{ZrO}_{2}$ ), as well as supports of a different crystalline state - amorphous zirconia and titania have been used $(24,26,27)$. The data obtained for WCS activity are given in Table 1. Gold deposited on well-crystallized metal oxides exhibits higher activity than that on amorphous oxides. The same is true for the mixed oxide supports.

Recently, it was found that gold deposited on ceria is very effective in the WCS (29), and the influence of gold loading on the high catalytic activity and stability of $\mathrm{Au} / \mathrm{CeO}_{2}$ was studied. The catalytic activity measurements performed in our laboratory are summarized in Figure 1 (22, 24, 26, 27, 29). It can be seen that gold deposited on iron and cerium oxides and on well crystallized titania and zirconia gave good low temperature WGS activity.

The results obtained for the catalytic activity of different gold catalysts give rise to questions about the influence of the nature of the support, the choice of the preparation 
method, the influence of gold on the reducibility of the metal oxide support and certainly on the WGS reaction mechanism. These questions, which are interrelated to a great extent, will be considered in the following sections.

\section{Influence of Preparation Techniques}

Three preparation techniques were employed: 1 Coprecipitation (CP) - gold hydroxide was precipitated simultaneously with the corresponding metal hydroxide; 2 Deposition-precipitation (DP) - gold hydroxide was deposited on the metal oxide previously suspended in water; 3 Modified version of the depositionprecipitation technique (MDP) - gold hydroxide was deposited on the freshly precipitated metal hydroxide. Table 2 summarizes the results obtained on the influence of the preparation technique on gold dispersion and WGS activity. The detailed preparation conditions are described elsewhere (22, 24 - 27, 29). Temperature, $\mathrm{pH}$, stirrer speed, feed flow rate, time of ageing, thermal treatment, etc all exert strong influences on the structure and properties of the catalysts. The gold catalysts having the oxides of iron, cobalt, nickel or manganese as support, are usually prepared by the CP method (22, 24, 30 32). However, our MDP method with the above-mentioned metal oxides, yielded samples of increased catalytic activity in the $\operatorname{WGS}(24,25)$ (see Table 2 and Figure 1). For the gold/iron oxide catalyst, prepared by the MDP method, we observed high gold dispersion and prevention of gold aggregation. On the other hand, the major part of the gold particles remains on the iron oxide surface, thus being accessible for catalysis (25). The $\mathrm{Au} / \mathrm{CO}_{3} \mathrm{O}_{4}$ (MDP) sample also exhibited higher activity than the $\mathrm{Au} / \mathrm{CO}_{3} \mathrm{O}_{4}(\mathrm{CP})$ sample. It was shown for the gold/iron oxide catalyst (22) that gold hydroxide precipitation at a constant $\mathrm{pH}$ yields gold particles of higher dispersion than those obtained by gradually increasing $\mathrm{pH}$ to the desired value. As a result, significantly lower CO conversion was registered over the latter sample compared with the former (22).

Particularly drastic differences in the catalytic activity as a function of the method of preparation were observed for the $\mathrm{Au} / \mathrm{TiO}_{2}$ and $\mathrm{Au} / \mathrm{ZrO}_{2}$ catalysts (Figure 1) $(24,26)$. Samples, prepared by the MDP technique had significantly lower catalytic activity than those prepared by DP on well-crystallized oxides, irrespective of the higher dispersion of the gold particles in the former case. The choice of the preparation method clearly has to be considered as well as the nature of the support used.

\section{Effect of Particle Size}

As was observed for other reactions, the WGS activity of goldbased catalysts is sensitive to the size of the gold particles. The preparation method has a crucial influence on obtaining highly
Table 2 Average Size of Gold Particles of the Gold-Based Catalysts on Different Supports, Prepared by Different Methods*

\begin{tabular}{|c|c|c|}
\hline Catalysts $^{1}$ & $\begin{array}{l}\mathrm{d}_{\mathrm{Au}}{ }^{2} \\
\mathrm{~nm}\end{array}$ & $\begin{array}{c}\mathrm{t}_{1 / 2}{ }^{3} \\
{ }^{\circ} \mathrm{C}\end{array}$ \\
\hline $\mathrm{Au} / \mathrm{Fe}_{2} \mathrm{O}_{3}(\mathrm{CP})$ & 4.0 & 160 \\
\hline $\mathrm{Au} / \mathrm{Fe}_{2} \mathrm{O}_{3}(\mathrm{CP})$ & $>10.0$ & 280 \\
\hline $\mathrm{Au} / \mathrm{Fe}_{2} \mathrm{O}_{3}(\mathrm{MDP})$ & 3.5 & 150 \\
\hline $\mathrm{Au} / \mathrm{CO}_{3} \mathrm{O}_{4}(\mathrm{CP})$ & 8.0 & 235 \\
\hline $\mathrm{Au} / \mathrm{CO}_{3} \mathrm{O}_{4}(\mathrm{MDP})$ & 7.0 & 200 \\
\hline $\mathrm{Au} / \mathrm{TiO}_{2}$ (DP) & $<5.0$ & 130 \\
\hline $\mathrm{Au} / \mathrm{TiO}_{2}$ (MDP) & $<3.0$ & 300 \\
\hline $\mathrm{Au} / \mathrm{ZrO}_{2}$ (DP) & $<5.0$ & 150 \\
\hline $\mathrm{Au} / \mathrm{ZrO}_{2}(\mathrm{MDP})$ & $<3.0$ & 300 \\
\hline $\mathrm{Au} / \mathrm{CeO}_{2}(\mathrm{DP})$ & 4.5 & $200^{4}$ \\
\hline \multicolumn{3}{|c|}{$\begin{array}{l}{ }^{1} \text { Cold amount is } 3 \text { wt\% } \\
{ }^{2} \text { Calculated from XRD using Scherrer's equation and TEM data } \\
3 \text { Temperature for } 50 \% \text { conversion } \\
{ }^{4} \text { This value is after } 3 \text { weeks of operation }\end{array}$} \\
\hline
\end{tabular}

dispersed gold particles, but the nature of the support also plays an important role. This was indicated by the results from different catalytic systems (Table 2, Figure 1). We have obtained differences in the size of gold particles ( $3.5 \mathrm{or}>10 \mathrm{~nm}$ ) in the $\mathrm{Au} / \mathrm{Fe}_{2} \mathrm{O}_{3}$ catalysts by varying the $\mathrm{pH}$, which directly affects the WCS activity (22). The effects arising from the preparative method employed and from the nature of the support on the gold dispersion can be seen in Table 2. Applying the same preparation method for the $\mathrm{Au} / \mathrm{Fe}_{2} \mathrm{O}_{3}, \mathrm{Au} / \mathrm{CO}_{3} \mathrm{O}_{4}$ and $\mathrm{Au} / \mathrm{TiO}_{2}$ catalytic systems yielded gold particles with different dispersion - the highest for $\mathrm{Au} / \mathrm{TiO}_{2}$ and the lowest - for $\mathrm{Au} / \mathrm{CO}_{3} \mathrm{O}_{4}$ (24).

For the $\mathrm{Au} / \mathrm{TiO}_{2}$ samples prepared by the MDP method, the WCS activity significantly decreases even although STEM indicates a higher dispersion of the gold particles than in the sample prepared by DP (24). Our investigations using XPS revealed that the first sample (MDP) contains about $86 \%$ small clusters, while that synthesized by DP contains the same percentage of large clusters (Table 3) (33). These results were unexpected. Recently, Valden and Goodman (34) have found that gold clusters supported on titania are related to a quantum size effect with respect to their thickness. Clusters of about $3.0 \mathrm{~nm}$ size are optimum and exhibit maximum $\mathrm{CO}$ oxidation activity, higher than the smaller and the larger ones. This study offers a satisfactory explanation of the results obtained by Bambeda et al (35) for CO oxidation activity over $\mathrm{Au} / \mathrm{TiO}_{2}$ catalysts. The quite different WCS activity of both of the $\mathrm{Au} / \mathrm{TiO}_{2}$ catalysts we studied can also be related to the presence of gold clusters of different size $(24,26$, 
Table 3 Binding Energies of Au $4 f_{7 / 2}$ Core Electrons and Peak Areas in $\mathrm{Au} / \mathrm{TiO}_{2}$ Catalysts, Prepared by Different Techniques*

\begin{tabular}{|lccccc} 
& \multicolumn{2}{c}{$\mathrm{Au} / \mathrm{TiO}_{2}$ (MDP) } & \multicolumn{2}{c}{$\mathrm{Au} / \mathrm{TiO}_{2}$ (DP) } \\
& $\mathrm{BE}(\mathrm{eV})$ & area (\%) & $\mathrm{BE}(\mathrm{eV})$ & area (\%) \\
\hline Au (large crystallites) & 84.36 & 14.4 & 84.40 & 86.0 \\
\hline Au (small crystallites) & 85.98 & 85.6 & 86.08 & 14.0
\end{tabular}

* Based on results given in reference 33

33). The catalysts containing the gold particles below $2.0-2.5$ $\mathrm{nm}$ do not exhibit high WCS activity.

One of the problems in using gold catalysts for WGS is the activity loss during catalysis. This problem is connected with the stability of the gold dispersion, because the main reason for the fast deactivation of these catalysts is the agglomeration of the gold particles. Our recent studies on $\mathrm{Au} / \mathrm{CeO}_{2}$ catalysts have demonstrated their very stable catalytic activity for WCS, which can be related to the high and stable dispersion of gold on ceria (29). The optimum size of the gold particles for WGS for this catalyst is between 3 and $5 \mathrm{~nm}$.

\section{Effect of the Support}

The nature of the support is of decisive importance for the catalytic activity of gold catalysts. The search for better supports is one of the main research tasks. There is evidence that the activity of gold catalysts depends on the specific interaction between the gold particles and the support. Our investigations revealed that gold deposition on iron oxide, titania or zirconia yields LT WGS catalysts having good performance (21, 22, 24 26). Cobalt oxide is not an appropriate support for gold WCS catalysts, although it is good for other reactions, eg CO oxidation $(30,31)$. Both the state and the structure of the support define the activity and stability of the gold catalysts. It should be noted that the support precursors also play an important role (3638). As was mentioned above, WCS activity of samples with freshly prepared $\mathrm{Ti}(\mathrm{OH})_{4}$ or $\mathrm{Zr}(\mathrm{OH})_{4}$ supports was significantly lower than samples obtained with well crystallized titania and zirconia under the same conditions $(24,26)$. The effect of the support's precursor was studied by Kozlova et al (36) who have found that the use of amorphous as-precipitated iron-hydroxide $\mathrm{Fe}(\mathrm{OH})_{3}{ }^{*}$ permits the preparation of highly active gold catalysts for LT CO oxidation. Baiker et al $(37,38)$ showed that the degree of crystallization of zirconia supports for gold, silver and copper catalysts strongly affects their activity for methanol synthesis and reverse WGS. They found that the crystallization of amorphous zirconia results in significantly lower activity and selectivity in the above reactions (37). Taking into account the above-mentioned considerations, we prepared gold catalysts on amorphous or not well-crystallized zirconia, zinc oxide and the mixed oxide systems
$\mathrm{Fe}_{2} \mathrm{O}_{3}-\mathrm{ZnO}$ and $\mathrm{Fe}_{2} \mathrm{O}_{3}-\mathrm{ZrO}_{2}$. We found that WGS activity of gold catalysts on well crystallized iron, titania and zirconia were higher in comparison with that of samples on the corresponding amorphous oxides $(24,26,27)$ (Table 1). The reason for using the mixed oxide support was both to retard the crystallization of iron oxide and to obtain a non-stoichiometric spinel structure (27). The presence of gold resulted in enhanced formation of non-stoichiometric $\gamma$ - $\mathrm{Fe}_{2} \mathrm{O}_{3}$ spinel phase, which exhibited higher activity for WCS than magnetite (39). The data obtained showed the relation between the nature of the support, its state and structure and their influence on gold dispersion, which reflect on the WGS activity of gold catalysts. One possible explanation for the observed differences in the catalytic behaviour of the catalysts studied by Baiker (37) and those prepared in our laboratory could be related to the difference in size of the metal particles - $3.4 \mathrm{~nm}$ in the former case and below $3 \mathrm{~nm}$ in the latter. As stated above, a $2.5-3 \mathrm{~nm}$ particle size is crucial for WGS activity.

Recently we found that ceria is a very good support for gold catalysts. Owing to its high oxygen storage capacity, ceria acts as an active support for the WGS (29). Deposition of gold on ceria leads not only to a high WGS activity: for the first time high stability over a long time of catalysis was recorded for these catalysts. The sample with 3wt\% Au displayed higher activity and stability in comparison with the samples with 1 and 5 wt\%. It may therefore be concluded that this sample has the optimum ratio between the number of gold active centres and the free ceria surface, which provides a source of oxygen from the support.

\section{Effect of Gold on the Reducibility of the Metal Oxide Support}

Special attention should be paid to the influence of gold on the reducibility of the metal oxide support. The data obtained for the temperature-programmed reduction (TPR) measurements on the catalysts based on iron and cobalt oxides are indicated in Figure 2. The TPR of the $\mathrm{Au} / \mathrm{Fe}_{2} \mathrm{O}_{3}$ catalytic system (Figure $1 \mathrm{~A}$ ) revealed that gold promotes only the first reduction step (hematite $\rightarrow$ magnetite) and the reduction temperature is significantly lower (about $140^{\circ} \mathrm{C}$ ) in comparison with the pure $\mathrm{Fe}_{2} \mathrm{O}_{3}$ (40). Such enhanced reduction of the support was also observed for supported Pt, $\mathrm{Pd}$ and Rh catalysts. This was explained in terms of the activation of hydrogen on the metal and the spillover of the atomic hydrogen to the support $(35,41)$. In 1996, there was no evidence for the ability of gold to dissociate hydrogen. The study of the $\mathrm{Au} / \mathrm{Fe}_{2} \mathrm{O}_{3}$ catalytic system by IR spectroscopy and TPD measurements pointed to a substantial (about 2fold) increase in $\mathrm{OH}$ groups and non-dissociatively bonded water molecules on the gold-containing samples in 


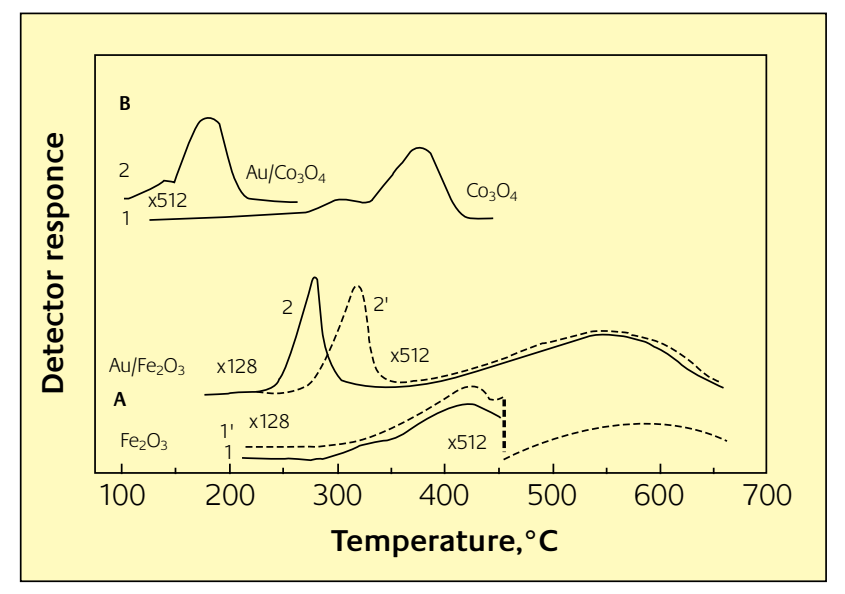

Figure 2

TPR spectra of the samples: (A): $1-\mathrm{Fe}_{2} \mathrm{O}_{3} ; 2-\mathrm{Au} / \mathrm{Fe}_{2} \mathrm{O}_{3} ; 1^{\prime}-\mathrm{Fe}_{2} \mathrm{O}_{3}$ after preliminary dehydroxylation; 2' - $\mathrm{Au} / \mathrm{Fe}_{2} \mathrm{O}_{3}$ after preliminary dehydroxylation; (B) $1-\mathrm{CO}_{3} \mathrm{O}_{4} ; 2-\mathrm{Au} / \mathrm{CO}_{3} \mathrm{O}_{4}$ (based on references 40, 43)

comparison with non-promoted $\mathrm{Fe}_{2} \mathrm{O}_{3}$ (40). The TPR spectra of the $\mathrm{Fe}_{2} \mathrm{O}_{3}$ and $\mathrm{Au} / \mathrm{Fe}_{2} \mathrm{O}_{3}$ samples after dehydroxylation (Figure $2 \mathrm{~A}-1^{\prime}, \mathrm{2}^{\prime}$ ) shows that the peak due to the reduction step $\mathrm{Fe}_{2} \mathrm{O}_{3} \rightarrow \mathrm{Fe}_{3} \mathrm{O}_{4}$ is shifted to higher temperatures, but remains lower than that for the same step obtained in the absence of gold. A probable explanation of the results obtained by TPR and TPD (a continuous desorption of water up to $800^{\circ} \mathrm{C}$ after the first well resolved peak) for the $\mathrm{Au} / \mathrm{Fe}_{2} \mathrm{O}_{3}$ sample, can be related to incorporation of part of the desorbed water in a cycle, represented by Scheme 1 (40).

Our further investigations by FTIR pointed to the presence of dissociated hydrogen on the small gold particles in both $\mathrm{Au} / \mathrm{TiO}_{2}$ and $\mathrm{Au} / \mathrm{Fe}_{2} \mathrm{O}_{3}$ even at room temperature, giving rise to hydrogen atoms, which by spillover onto the support can reduce its surface sites (42). The XPS measurements also gave evidence for the partial reduction of the support $\left(\mathrm{Ti}^{3+}\right)$ in $\mathrm{Au} / \mathrm{TiO}_{2}$ (33). These results confirmed the reactivity of small gold particles to produce active hydrogen.

Enhanced reduction of the support in the presence of gold was also established for the $\mathrm{Au} / \mathrm{CO}_{3} \mathrm{O}_{4}$ catalysts (Figure 2B). The reduction temperature is $\mathrm{Ca} 200^{\circ} \mathrm{C}$ lower than with pure $\mathrm{CO}_{3} \mathrm{O}_{4}$. In this case, however, the reduction of $\mathrm{CO}_{3} \mathrm{O}_{4}$ goes to elemental

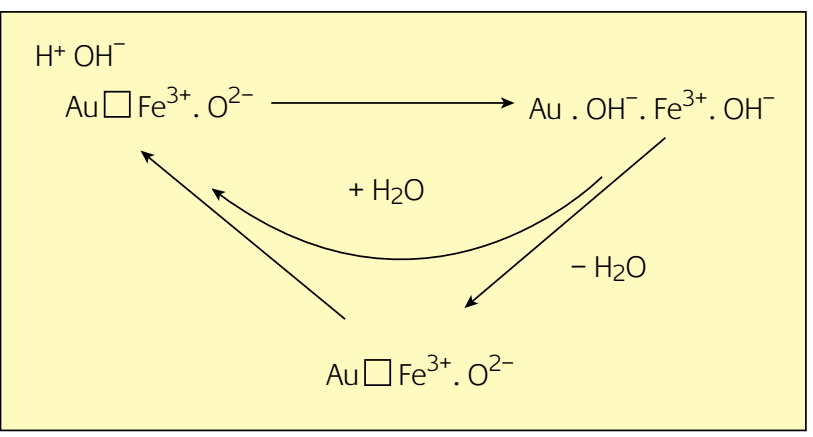

\section{Scheme 1}
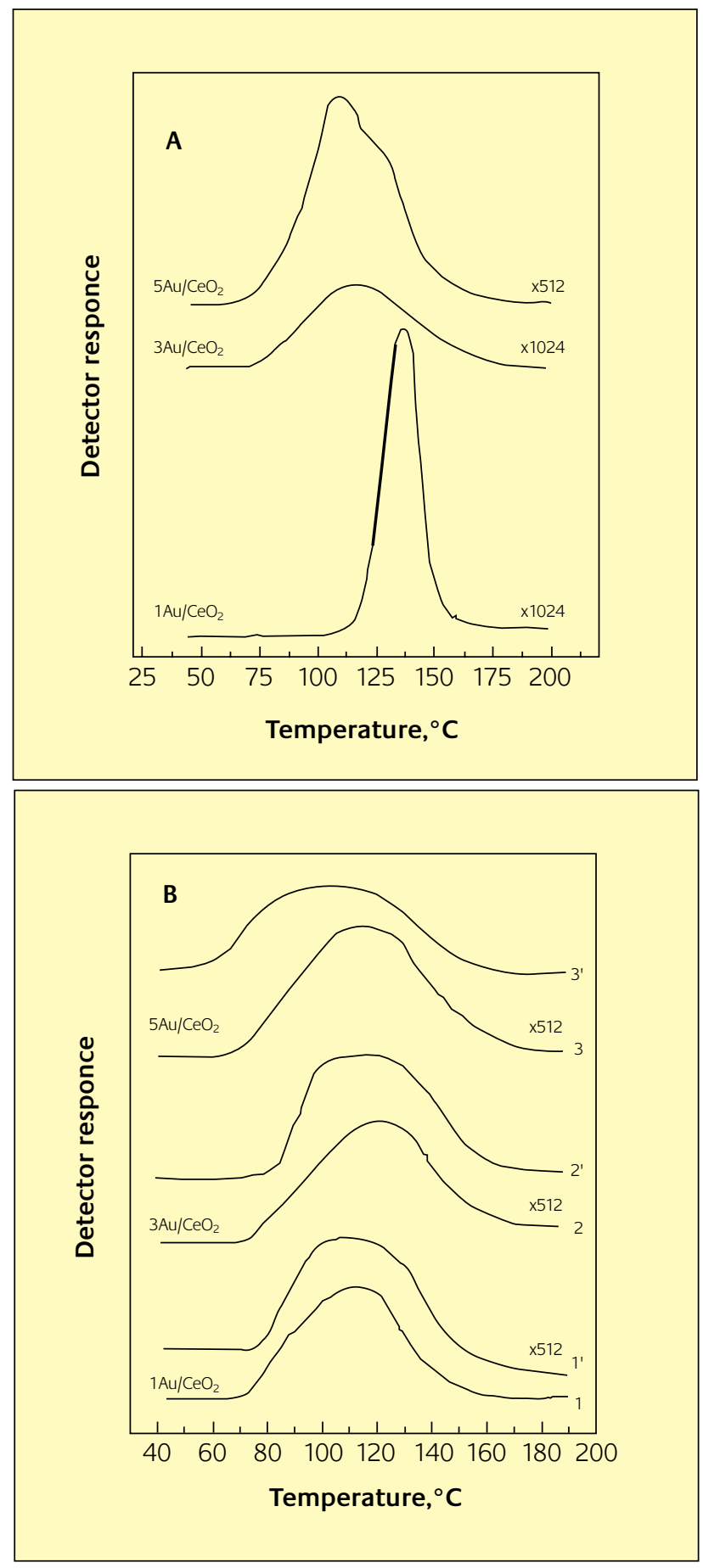

\section{Figure 3}

TPR spectra of the $\mathrm{Au} / \mathrm{CeO}_{2}$ samples: $(\mathrm{A})$ : fresh samples with different gold loading (1, 3 and 5 wt\% gold, respectively); (B) reoxidation after first reduction peak: at room temperature (1,2 and 3 curves) and at $200^{\circ} \mathrm{C}\left(1^{\prime}, 2\right.$ ' and 3') (based on reference 29)

cobalt in one step. This is the main reason for the fast deactivation of $\mathrm{Au} / \mathrm{CO}_{3} \mathrm{O}_{4}$ catalysts in the WCS $(24,43)$. TPR measurements also indicated enhanced reduction of the support for the $\mathrm{Au} / \mathrm{Ni}(\mathrm{OH})_{2}$ catalyst (44). During the catalytic operation in the WCS reaction, the major part of support was 
reduced to elemental nickel and the yield of methane became predominant (ie a high methanation activity was detected) (44).

Claus et al have recently observed paramagnetic F-centres in the support for both $\mathrm{Au} / \mathrm{TiO}_{2}$ and $\mathrm{Au} / \mathrm{ZrO} 2$ samples containing extremely small gold particles (45). These results are in agreement with our data which indicates enhanced reduction of the metal oxide supports in the presence of nano-sized gold particles.

The TPR measurements on the $\mathrm{Au} / \mathrm{CeO}_{2}$ catalysts showed that the presence of gold only influences the reduction of ceria at the surface and not in the bulk (Figure 3A) (29). Depending on the gold loading, a reduction peak of complex shape and different position was observed. The hydrogen consumption could arise from two processes, one of which could be related to the reduction of oxygen species on the fine gold particles and the second from reduction of surface ceria. The additional experiments with reoxidation of the catalysts at room temperature and $200^{\circ} \mathrm{C}$ indicated the high oxygen storage capacity of these catalysts (Figure 3B). The results provided evidence for the reduction/oxidation processes taking place at significantly lower temperatures, even at room temperature in the presence of gold. This behaviour could be connected with the high and stable WGS activity of gold/ceria catalysts (29).

It was of interest to compare the TPR spectra of the oxide supports with those having gold nanoparticles, not only qualitatively, an approach used in many papers, but to estimate the respective kinetic parameters of the reduction process. The kinetic parameters were evaluated by simulation of experimental TPR spectra for the $\mathrm{Au} / \mathrm{Fe}_{2} \mathrm{O}_{3}$ and $\mathrm{Au} / \mathrm{CO}_{3} \mathrm{O}_{4}$ catalytic systems. It was established that in the case of the $\mathrm{Au} / \mathrm{Fe}_{2} \mathrm{O}_{3}$ (for the first reduction step: hematite to magnetite) the pre-exponential factor value is substantially higher than that for pure $\mathrm{Fe}_{2} \mathrm{O}_{3}$ (46). In the case of $\mathrm{Au} / \mathrm{CO}_{3} \mathrm{O}_{4}$, the presence of gold influenced both the activation energy and the pre-exponential factor of the reduction process (43).

\section{Reaction Mechanism}

It is known that iron oxide catalysts are very active in the WCS at high temperatures, while titania is practically inactive in this reaction. The almost equal activities of the $\mathrm{Au} / \mathrm{Fe}_{2} \mathrm{O}_{3}$ and $\mathrm{Au} / \mathrm{TiO}_{2}$ catalytic systems observed in our work, give rise to the need to define the reaction mechanism (24). The FIIR study (42) of the adsorption of the molecules involved in the WGS and reverse WGS reactions on $\mathrm{Au} / \mathrm{Fe}_{2} \mathrm{O}_{3}$ and $\mathrm{Au} / \mathrm{TiO}_{2}$ catalysts, and their coadsorptions and reactive interaction at room temperature and $250^{\circ} \mathrm{C}$ revealed that the active sites for the water-CO reactive interaction are located on the surface of the small metallic gold particles. On the basis of the results obtained, a redox regenerative mechanism was proposed (42). Upon increasing the temperature to $250^{\circ} \mathrm{C}$, two weak bands at 2930 and 2851 $\mathrm{cm}^{-1}$ were registered which could be assigned to the $\mathrm{C}-\mathrm{H}$ stretching mode of a formate species produced by bicarbonate decomposition. Since bicarbonates could also be intermediates in the WCS $(3,47)$ and the WGS activity was measured in the temperature range $140-250^{\circ} \mathrm{C}$, an alternative route for the WGS via an associative mechanism could be suggested. By quantum chemical calculations for the $\mathrm{CO}-\mathrm{H}_{2} \mathrm{O}$ adsorption on $\mathrm{Pt}$ it was found that $\mathrm{E}_{\mathrm{a}}$ of water adsorption is $0.86 \mathrm{eV}$ when water is adsorbed dissociatively as $\mathrm{H}_{a}$ and $\mathrm{OH}_{a}$ and $1.23 \mathrm{eV}$ via $\mathrm{O}_{a}$ and $\mathrm{H}_{\mathrm{a}}$ dissociation (48). The results obtained supported the associative mechanism of WCS on supported platinum and may be regarded as a confirmation of the above-mentioned two probable mechanistic routes for the WGS on gold-based catalysts.

The role of the support is very important due to its ability, depending on its nature, to modify the electronic properties of the small gold particles. In the case of ceria, our results showed that the sample with 3 wt\% Au exhibits higher activity and stability than the samples with 1 and $5 w t \%$. This means that the support plays an active role in the reaction, because of the need for enough free support surface area. This could be indirect evidence for another mechanism for the WGS, involving participation of the support, see Scheme 2.

\section{Conclusions}

To achieve high activity and stability for gold catalysts in the WCS, several factors should be combined:

1 Choice of an appropriate support for every catalytic process with a view to providing a good interaction between gold and the support and a high and stable dispersion of the gold particles on it.

2 High WGS activity is displayed by gold particles with an optimum size of 3 - $5 \mathrm{~nm}$.

3 The support can modify the electronic properties of nano-

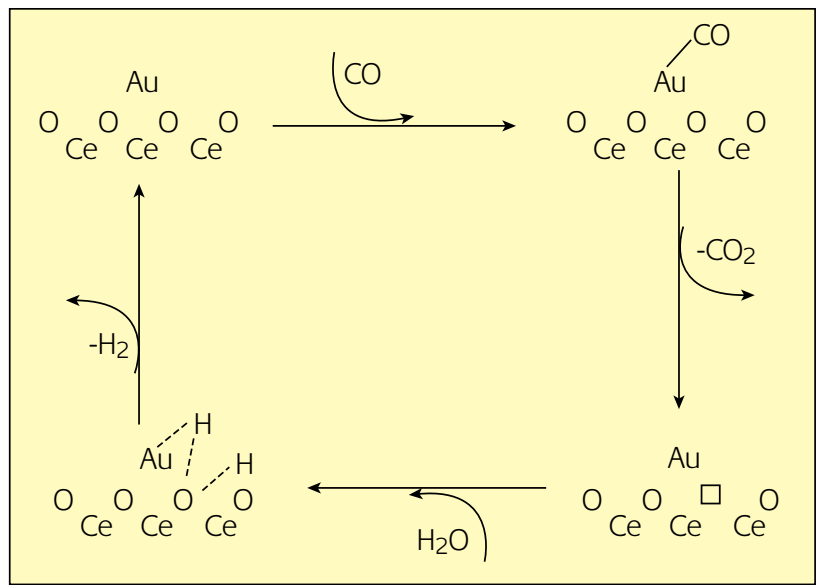

Scheme 2 
sized gold particles and this interaction defines the precise nature of the structure and properties at the gold/support interface.

4 The choice of the preparation method should consider the nature of the support, aiming at providing good contact between gold and the support, high gold dispersion and uniform distribution on the surface.

5 A knowledge of the various aspects of the reaction mechanism is of a great significance for assistance in the design and selection of highly active catalysts.

\section{About the Author}

Dr Donka Andreeva is an Associate Professor at the Institute of Catalysis, Bulgarian Academy of Sciences (BAS). She was awarded her PhD degree in 1981 in the Department of Catalysis, BAS, and has worked for 30 years in the field of heterogeneous catalysis. Her experience has included design and selection of metal and metal oxide catalysts, catalyst characterization and reaction mechanisms. Her interest in catalysis by gold dates from 1995.

\section{References}

1 K. Kochloefl, in 'Handbook of Heterogeneous Catalysis', ed. G. Ertl, H. Knozinger and J. Weitkamp, 1997, 4, 1831

2 D.S. Newsome, Catal. Rev. - Sci. Eng., 1980, 21, 275

3 A. Andreev, T. Halachev and D. Shopov, Bulg. Chem. Comm., 1988, 21, 307

4 C. Rhodes, G.J. Hutchings and A.M. Ward, Catal. Today, 1995, 23, 43

5 D.C. Grenoble, M.M. Estadt and D.S. Ollis, J. Catal., 1981, 67, 90

6 L. Mendelovici and M. Steinberg, J. Catal., 1985, 96, 285

7 B.I. Whittington, C.J. Jiang and D.L. Trimm, Catal. Today, 1995, 26, 41

8 Y. Li, Qi Fu and M. Flytzani-Stephanopolos, Appl. Catal. B: Environmental, 2000, 27, 17

9 S. Hilaire, X. Wang, T. Luo, R.J. Gorte and J. Wagner, Appl. Catal. A: General, 2001, 215, 271

10 T. Shido and Y. Iwasawa, J. Catal., 1993, 141, 71

11 A. Andreev et al, Bulgarian Patent 62040 (1995)

12 M. Haruta, Catal. Surveys Jpn., 1997, 1, 61

13 M. Haruta, Catal. Today, 1997, 36, 153

14 M. Haruta, N. Yamada, T. Kobayashi and S. lijima, J. Catal., 1989, 115, 301

15 S. Tsubota, D.A.H. Cunningham, Y. Bando and M. Haruta, in: ‘Preparation of Catalysts VI', ed. G. Poncelet et al., Elsevier, Amsterdam, 1995, p.227

16 L.D. Burke, Platinum Metals Rev., 1994, 38, 166

17 L.D. Burke, Gold Bull., 1998, 31, 39

18 G.C. Bond and D.T. Thompson, Catal. Rev. - Sci. Eng., 1999, 41, 319

19 G.C. Bond and D.T. Thompson, Gold Bull., 2000, 33, 41

20 H. Sakurai, S. Tsubota and M. Haruta, Appl. Catal. A, 1993, 102, 125

21 D. Andreeva, V. Idakiev, T. Tabakova and A. Andreev, J. Catal., 1996, 158,354 Catal. A: General, 1996, 134, 275

23 D. Shiskov et al, Bulgarian Patent 38192 (1985)

24 D. Andreeva, V. Idakiev, T. Tabakova and R. Giovanoli, Bulg. Chem. Comm., 1998, 30, 59

25 D. Andreeva, T. Tabakova, V. Idakiev, P. Christov and R. Giovanoli, Appl. Catal. A: General, 1998, 169, 9

26 T. Tabakova, V. Idakiev and D. Andreeva, Proc. 9th Intern. Symposium Heterog. Catal., ed. L. Petrov, Ch. Bonev and G. Kadinov), 2-27 September, Varna, 2000, p. 489

27 T. Tabakova, V. Idakiev, D. Andreeva and I. Mitov, Appl. Catal. A: General, 2000, 202, 91

28 H. Sakurai, A. Ueda, T. Kobayashi and M. Haruta, Chem. Commun., 1997, 271

29 D. Andreeva, V. Idakiev, T. Tabakova, L. llieva, P. Falaras, A. Bourlinos and A. Travlos, Catal. Today, 72 (2002) 51

30 M. Haruta, T. Kobayashi, S. lijima and F. Delannay, Proc. 9th Int. Congress on Catalysis, Calgary, 1988, p. 1206

31 M. Haruta, S. Tsubota, T. Kobayashi, H. Kageyama, M. Genet and B. Delmon, J. Catal., 1993, 144, 175

32 R.D. Waters, J.J. Weimer and J.E. Smith, Catal. Lett., 1995, 30, 181

33 J. Sobczak and D. Andreeva, Stud. Surf. Sci. Catal., 2000, 130, 3303

34 M. Valden, X. Zai and D.W. Goodman, Science, 1998, 281, 1647

35 B. Harrison, A.F. Diwell and C. Hallett, Platinum Metals Rev., 1988, 32, 73

36 A. Kozlova, S. Sugiyama, A. Kozlov, K. Asakura and Y. Iwasawa, J. Catal., 1998, 176, 426

37 A. Baiker, M. Kilo, M. Maciejewski, S. Menzi and A. Wokaun, Proc. 10th Int. Congress on Catalysis, Budapest, 1992, Part B, ed. L. Guczi, F. Salamosi and P. Tetenyi, Elsevier Science Publ. B.V., 1993, p. 1257

38 A. Baiker, M. Maciejewski, S. Tagliaferri and P. Hug, J. Catal., 1995, 151, 407

39 I. Mitov, D. Andreeva, V. Mitrov and A. Andreev, Proc. 8th Int. Symp. Heter. Catal., Varna, 1996, Part 1, ed. A. Andreev, L. Petrov, Ch. Bonev, G. Kadinov and I. Mitov, M. Drinov Publ. House, Sofia, 1996, p. 171

40 L. Ilieva, D. Andreeva and A. Andreev, Therm. Acta, 1997, 292, 169

41 W. Conner, Jr., G.M. Pajonk, and S.J. Teishner, in 'Advances in Catalysis' ed. D.D. Eley, H. Pines, and P.B. Weisz, Academic Press, San Diego, CA, 1986, 34, p.1

42 F. Boccuzzi, A. Chiorino, M. Manzoli, D. Andreeva and T. Tabakova, J. Catal., 1999, 188, 176

43 L. llieva, G. Munteanu and D. Andreeva, Bulg. Chem. Comm., 1998, 30, 378

44 A. Andreev, L. Mintchev, T. Tabakova, V. Idakiev, P. Christov and D. Andreeva, Proc. 9th Intern. Symp. Heterog. Catal., ed. L. Petrov, Ch. Bonev and G. Kadinov, 2-27 September, Varna, 2000, p. 141

45 P. Claus, A. Bruckner, Ch. Mohr and H. Hofmeister, J. Am. Chem. Soc., 2000, 122, 11430

46 G. Munteanu, L. llieva and D. Andreeva, Therm. Acta, 1997, 291, 171

47 D.G. Retwisch and J.A. Dumesic, Appl. Catal., 1986, 21, 97

48 A. Anderson, N. Neshev, R.A. Sidik and P. Shiller, J. Chem. Phys., submitted 